\title{
Analyzing the Deformation of Multilayered Saturated Sandy Soils under Large Building Foundation
}

\author{
Chun Li“*\#, Zhanguo Xiu**\#, Yingchun Ji***, Feili Wang****, A.H.C.Chan ${ }^{* * * * *}$
}

\begin{abstract}
The generalized plasticity theory has been subject of much research in geomechanics. The Pastor-Zienkiewicz model and its modified versions are among these. For large foundations resting on multilayered soils the actual loading are often non-linear. In this study we developed a new mathematical model which can apply non-linear loading using the subfield of planar mesh method. A sensitivity study was first performed to evaluate the contribution of deformation from various model parameters. It is found that the plastic modulus parameters only have marginal contributions. An engineering case study was used to valid the proposed model and it is evident from measured stresses that the loading of the foundation is non-linear. The deformations calculated by the proposal model agreed well with the monitored deformations. It is also found that the maximum deformation point is not necessarily in the centre of foundation and it does not coincide with the maximum loading point either. The distance between the maximum deformation point and the maximum loading point can be as far as $15.59 \mathrm{~m}$ for the bottom layer soil from this case. This research proves the necessity of using non-linear loading to calculate the foundation deformations for large foundations with multilayered saturated soils.
\end{abstract}

Key words : large building foundation, Pastor-Zienkiewicz model, sensitivity analysis, foundation deformation, multilayered soils

\section{Introduction}

Early 1980s a generalized plasticity theory was proposed by (Zienkiewicz OC and Mroz Z, 1984; Mroz Z and Zienkiewicz OC, 1984 ) for modelling the non-linear behavior of real materials such as soil. In this generalized plasticity theory direction vectors were used and the yield and plastic potential surface do not need to be explicitly defined. This generalized plasticity theory does provide a relatively simple framework for predicting the behavior of geomaterials under different loading conditions (Ling HI and Liu H, 2003). The generalized plasticity theory was later extended by Zienkiewicz OC et al. (1985) and Pastor M et al. $(1985 ; 1986)$ and Pastor M and Zienkiewicz OC (1990) which led to the Pastor-Zienkiewicz model ( "P-Z model" hereafter). The P-Z model is a constitutive model primarily applied to geomaterials such as clay and sand ( $\mathrm{Li}$ et al., 2011). The $P-Z$ model is able to simulate the deformation behavior of sand under monotonic and cyclic loading conditions (Pastor M, 1986). There were also several other modifications to the generalized plasticity theory. Pastor $\mathrm{M}$ et al. (1990) proposed a modified non-linear Pastor-Zienkiewicz-Chen model without changing the number of model parameters, which performed better in predicting the dynamic liquefaction of saturated sand under undrained conditions (Amin Iraji et al., 2014). Based on the critical state and the generalized plasticity theory, Ling HI and Yang S (2006) modified the plastic modulus, loading vectors and plastic flow direction vectors to propose a unified generalized plasticity model for modelling the deformation behavior of sand under various loading conditions. The static part of the $P-Z$ model was also modified by Li et al. (2016) by introducing some state parameters into the dilatancy formula, plastic potential direction vector, loading (unloading) direction vectors and plastic modulus equation of the original P-Z model. Liu and Ling (2002), Liu and Song (2005) extended the generalized plasticity model to capture the dilatancy and strength properties of sand under a wide range of stress levels. Tonni L et al. (2006) introduced a state-dependent dilatancy and adjusted plastic modulus that based on the basic generalized plasticity theory to simulate the softening of dense sands. These models were all rooted from the generalized plasticity theory. It has been a common practice to modify the original plasticity theory by adjusting specific model parameters in order to solve specific engineering applications. *Professor, School of Resource and Civil Engineering, Northeastern University, Shenyang 110819, China; (E-mail: lichun@mail.neu.edu.cn)

**Student, School of Resource and Civil Engineering, Northeastern University, Shenyang 110819, China; (Corresponding Author, E-mail: xiuzhanguo109@126.com)

***Professor, School of the Built Environment, University of Salford, Salford, M5 4WT, UK (E-mail: Y.Ji@ salford.ac.uk)

****Student, School of Resource and Civil Engineering, Northeastern University, Shenyang 110819, China; ( E-mail: wangfeili109@126.com)

*****Professor, School of Engineering and Information Technology, Federation University of Australia, Ballarat 3353, Australia (E-mail: 2916147536@qq.com)

\#These authors are co-first authors of the article. 
For engineering practices such as foundation deformation calculation, the generalized plasticity theory was also used in association of the layer-wise summation method. In order to understand the deformation characteristics of layered soils, i.e., for the multi-layer elastic isotropic subsoil under strip foundation, Gazetas (1980) established a numerical calculation method to calculate the static and dynamic displacement of foundations. This numerical method can only be applied to the rigid and rough strip foundation. Onopa IA et al. (1983) monitored the settlement of the four-layer compacted and saturated silty soil under a single footing. The monitored results showed that different thickness of compressible soil layer in the foundation had different influence on the settlement. Bezvolev S.G. (2002) proposed a linear variable half-space model that was used to calculate the deformation at any point in the limited depth of the compressible soil. This is an improved layer-wise summation method. Denis et al. (2011) analyzed the potential influences on the security of foundation from the soil property - when the soil property was changed in longitudinal direction under the continuous spread footing. In foundation practices, this aspect was rarely considered in the past. Díaz E and Tomás R (2016) proposed a simple method to predict elastic settlements in foundation resting on two soils of differing deformability. By adjusting the reduction factor, the resulted maximum error was less than $1.57 \%$ between the actual measurements and calculated results.

The existing models discussed earlier are believed insufficient in calculating the deformation of multilayered soils under the large scale building foundations, in particular for the layered soils foundation with larger differences in soil properties. The above models tend to assume linear loading and uniform deformation across the foundation layers which may not be the case for large and complex foundations. Due to the large size of foundations and the complexity of building structures, the actual loading on the surface of such foundations can often be non-linear. The non-linear loading in this work refers to the fact that the overall distribution of the effective additional stress on the foundation surface under large-scale foundation is irregular (ref: Fig. 10c). Consequently the maximum loading point maybe not necessarily the point where the maximum deformation happens. The general $P-Z$ model was widely used to simulate the deformation under dynamic conditions such as earthquake and waves (Pastor M et al., 1985), but fewer applications on the analysis of soil deformation under lager scale building foundations under static loads. In static loading practices, the soil deformation is caused only by vertical loading, and once the load is on it will be there continuously (i.e. for large multi-storey or high rise buildings once constructed). Under this particular scenario, the loading that produced by the construction can be regarded as monotonic and continuous. Therefore a simplified P-Z model with less number of parameters can then be adopted to calculate the foundation deformations discussed in this research.

In this paper, a new mathematical model to determine the deformation of large foundation is proposed. A sensitivity analysis of parameters was done based on their individual contribution to the deformation of foundations. The concerned model parameters are: two parameters related to the elastic state: elastic modulus $\left(E_{0}\right)$ and Poisson's ratio $(\mu)$; two parameters for the critical state: internal friction angle $(\varphi)$ and relative density $\left(D_{\mathrm{r}}\right)$; and four parameters associated with plastic modulus: accumulated plastic deviatoric strain $(\xi)$, plastic modulus number $\left(H_{0}\right)$ and material parameters $\left(\beta_{0}\right.$ and $\left.\beta_{1}\right)$. The proposed mathematical model is constitutive, and deemed to be robust when performing deformation calculation for large foundations. By assessing the sensitivity of each parameter in the deformation calculation of foundations, the new mathematical model also provides important basis for the selection of parameters which can be used to guide experimental process. The paper is set out as follows: section 2 discusses the simplification of the P-Z model under static loading; section 3 describes the derivation of the new mathematical model using the subfield of planar mesh method; section 4 reports the sensitivity analysis of model parameters; model validation is carried out in section 5 using an engineering case study; followed by conclusion discussions in section 6 .

\section{The simplication of the P-Z model under static loading}

The $P-Z$ model was originally defined with $p-q-\theta$ coordinates. It was subsequently extended to the three-dimensional Cartesian coordinate system that is more convenient for model implementation and numerical simulations (Pastor M et al., 1990; Akhaveissy, 2011). In the process of simulating the deformation of sand, the non-associative flow rule $(\boldsymbol{f} \neq \boldsymbol{g})$ is used in this model. Akhaveissy et al. (2009) proposed the reformulated relations as general unit vectors to yield $(f)$ and the potential $(g)$ surfaces. These surfaces are schematically shown in Fig. 1. 


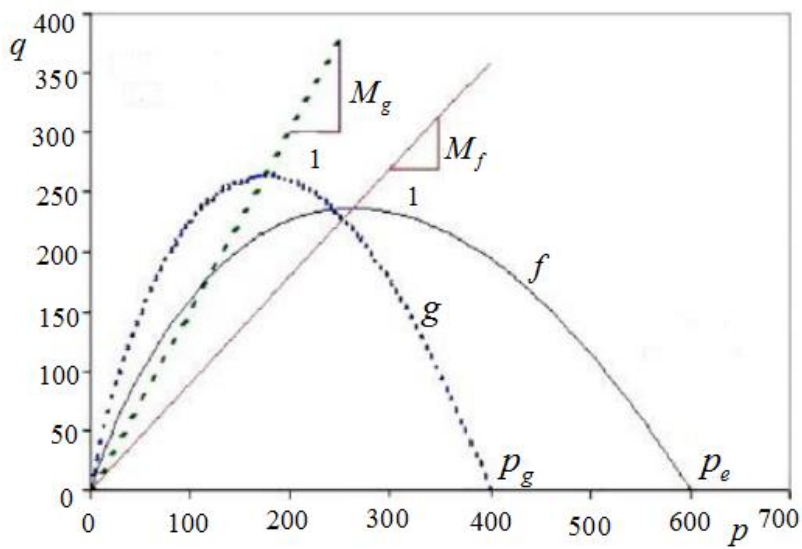

Fig. 1. Schematic yield and potential surfaces (Akhaveissy et al., 2009)

The equations of yield surface $(\boldsymbol{f})$ and potential surface $(\boldsymbol{g})$ are defined as follows:

$$
\left\{\begin{array}{l}
f=q-M_{f} \times(1+1 / \alpha) \times\left(1-\left(\frac{p}{p_{e}}\right)^{\alpha}\right) \\
g=q-M_{g} \times(1+1 / \alpha) \times\left(1-\left(\frac{p}{p_{g}}\right)^{\alpha}\right)
\end{array}\right.
$$

Where $f$ is the yield surface, $g$ is the plastic potential surface, $q$ is the deviatoric stress, $M_{f}$ is the model parameter controlling the loading direction, $p$ is the mean effective stress, $\alpha$ is the material constant, $p_{e}$ and $p_{g}$ are initial standard stress, and $M_{g}$ is the slope of the critical state line (CSL) that determined by the internal friction angle $(\varphi)$ at the critical state and Lode's angle $(\theta)$ :

$$
\begin{aligned}
& M_{g}=\frac{6 \sin \varphi}{3-\sin \varphi \sin 3 \theta} \approx \frac{M_{f}}{D_{r}} \\
& -\frac{\pi}{6} \leq \theta=\frac{1}{3} \sin ^{-1}\left(\frac{-3 \sqrt{3}}{2} \frac{J_{3}}{\left(J_{2}\right)^{3 / 2}}\right) \leq \frac{\pi}{6}
\end{aligned}
$$

Where $D_{r}$ is the relative density of soil, $J_{2}$ is the second invariant of the deviatoric stress, and $J_{3}$ is the third invariant of deviatoric stress.

The unit direction vectors of yield surface $(\boldsymbol{f})$ and potential surface $(\boldsymbol{g})$ can be expressed as:

$$
\{n\}=\frac{\left\{\frac{\partial f}{\partial \sigma}\right\}}{\left[\left\{\frac{\partial f}{\partial \sigma}\right\}^{T}\left\{\frac{\partial f}{\partial \sigma}\right\}\right]^{1 / 2}} \quad \text { and } \quad\left\{n_{g L}\right\}=\frac{\left\{\frac{\partial g}{\partial \sigma}\right\}}{\left[\left\{\frac{\partial g}{\partial \sigma}\right\}^{T}\left\{\frac{\partial g}{\partial \sigma}\right\}\right]^{1 / 2}}
$$

Where $\boldsymbol{n}$ and $\boldsymbol{n}_{g \mathrm{~L}}$ are the unit direction vector.

The relation between the increments of stress and strain for a material can be defined as:

$$
\{d \sigma\}=\left[D^{e p}\right]\{d \varepsilon\}
$$

Where $d \sigma$ and $d E$ are the increments of stress and strain, $D^{e p}$ is the elastic-plastic tensor.

The elastic-plastic matrix $\left(\left[D^{e p}\right]\right)$ in generalized plasticity can be expressed as: 
Where $D^{e}$ is the elastic tensor, and $H_{L}$ is the plastic modulus.

For cases where only the virgin loading is present and there is no unloading and reloading, the plastic modulus $\left(H_{\mathrm{L}}\right)$ can be simplified as:

$$
H_{L}=H_{0} p H_{f}\left\{H_{v}+H_{s}\right\}
$$

with

$$
\left\{\begin{array}{l}
H_{f}=\left(1-\eta / \eta_{f}\right)^{4} \\
\eta_{f}=(1+1 / \alpha) M_{f} \\
H_{v}=1-\eta / M_{g} \\
H_{s}=\beta_{0} \beta_{1} \exp \left(-\beta_{0} \xi\right)
\end{array}\right.
$$

Where $H_{f}$ and $H_{v}$ are the functions for the stress ratio of plastic modulus, $H_{s}$ is the hardening function of deviatoric strain, $\eta$ and $\eta_{f}$ are the Stress ratio parameters, $H_{0}$ and $\beta_{0}$ and $\beta_{1}$ are the Non-dimensional model parameters, $\xi$ is the accumulated plastic deviatoric strain. And $H_{0}$ is calculated using the expression from $\mathrm{Li}$ et al. (2016) as below:

$$
H_{0}=\frac{1+e_{0}}{\lambda-\kappa}
$$

Where $e_{0}$ is the initial void ratio, $\kappa$ is the slope of unloading-reloading line, and $\lambda$ is the sope of virgin loading line.

In the original $P-Z$ model, plastic modulus is divided into two parts that are loading plastic modulus $\left(H_{\mathrm{L}}\right)$ and unloading plastic modulus $\left(H_{\mathrm{u}}\right)$. It should be noted that there is a multiplier $\left(H_{\mathrm{DM}}\right)$ named as discrete memory factor for cyclic loading or unloading-reloading in original formula (7). As observed in drained cyclic triaxial experiments by Pradhan T.B.S. et al. (1989), the dense sand shows lower stiffness at reloading rather than at virgin loading. The observation led to a modified $\left(H_{\mathrm{DM}}\right)$ to simulate the dynamic capability of the dense sand at reloading by Amin Iraji et al. (2014). But, in the engineering practices considered in this research, the soil deformation under large scale building foundation is deformed only by vertical loading, and there is no unloading after construction. The loading is then considered as monotonic and continuous. Based on this, for the first time loading, multiplier $\left(H_{\mathrm{DM}}\right)$ can be treated as a unit vector in the original model which led to the current simplified version of formula (7).

To implement the P-Z model using numerical methods, the formula (4) will be transformed from $p-q-\theta$ coordinates to the Cartesian coordinate system. It is worth noting that the transformation of the unit vector $\boldsymbol{n}_{\mathrm{gL}}$ is the same as $\boldsymbol{n}$, while the equation $\boldsymbol{g}$ and parameter $M_{g}$ are replaced with $\boldsymbol{f}$ and $M_{f}$ respectively. The unit vector $\boldsymbol{n}$ (same expression for $\boldsymbol{n}_{\mathrm{gL}}$ ) can be expressed in terms of $I_{1}, J_{2}$ and $\theta$, as below:

$$
\begin{aligned}
n & =B_{1} n_{1}+B_{2} n_{2}+B_{3} n_{3} \\
& =\left\{\frac{\partial f}{\partial I_{1}}\right\}\left\{\frac{\partial I_{1}}{\partial \sigma}\right\}+\left(\left\{\frac{\partial f}{\partial \sqrt{J_{2}}}\right\}-\frac{\tan \theta}{\sqrt{J_{2}}}\left\{\frac{\partial f}{\partial \theta}\right\}\right)\left\{\frac{\partial \sqrt{J_{2}}}{\partial \sigma}\right\} \\
& +\frac{\sqrt{3}}{2 \cos 3 \theta} \frac{1}{J_{2}^{3 / 2}}\left\{\frac{\partial J_{3}}{\partial \sigma}\right\}\left\{\frac{\partial f}{\partial \theta}\right\}
\end{aligned}
$$

Component descriptions of the unit vector $\boldsymbol{n}$ are: 
where $s_{i j}=\sigma_{i j}-p \delta_{i j}$ is deviator stress, while $\delta_{i j}$ is Kronecker delta. $I_{1}$ is the first invariant of the stress tensor, $\sigma_{i j}$ is the total stress between particles of rank $i$ and $j$.

The formula (5) can then be expanded as:

$$
\left\{\begin{array}{l}
d \sigma_{x} \\
d \sigma_{y} \\
d \sigma_{z} \\
d \tau_{x y} \\
d \tau_{y z} \\
d \tau_{z x}
\end{array}\right\}=\left[D^{e p}\right]\left\{\begin{array}{l}
d \varepsilon_{x} \\
d \varepsilon_{y} \\
d \varepsilon_{z} \\
d \gamma_{x y} \\
d \gamma_{y z} \\
d \gamma_{z x}
\end{array}\right\}
$$

Assuming that the deformation of soil is only reflected by the $z$ direction (vertical), the compressive modulus $\left(E_{s}\right)$ of soil can be simplified as below (expressed as the increment of the vertical stress and strain):

$$
E_{s}=\frac{d \sigma_{z}}{d \varepsilon_{z}}
$$

Formula (14) comes directly from elastic mechanics but was modified based on the assumptions of $d \varepsilon_{x}=d \varepsilon_{y}=0$. The elastic-plastic matrix $\left[D^{e p}\right]$ in formula (13) is from the generalized plasticity theory which can be calculated by the P-Z model. Therefore, $E_{S}$ is able to calculate the plastic deformation of soil with vertical static loading. Once the elastic-plastic matrix $\left[D^{e p}\right]$ of the corresponding constitutive model is obtained, the modified compressive modulus $\left(E_{s}\right)$ can be determined.

\section{Derivation of the Mathematical Model}

The effective additional stress $\sigma_{0}$ under the large scale foundations includes the increments of effective stress and additional stress. The effective stress is resulted by the change of the unit weight $(\gamma)$ and pore water pressure $(u)$ of the soil. In this paper, a mathematical model will be established to calculate the deformation of saturated soils under a large scale building foundation. For this foundation model, the loading condition will remain unchanged after construction (once a building is built the structure load to its foundation will be static), the total stress increment $(\Delta \sigma)$ and the pore water pressure increment $(\Delta u)$ can then be assumed to be zero. Consequently, the effective stress increment will also be zero. In other words, the loading applied to the foundation by the building structure only changes during construction. Once the construction is finished, the effective additional stress is numerically equal to the maximum 
additional stress increment $\left(\sigma^{\prime}{ }_{0}\right.$ as shown in Fig. 2). Fig. 2 illustrates the saturated soil under a large foundation. The proposed mathematical model is developed based on this kind of raft type large scale foundation as shown below.

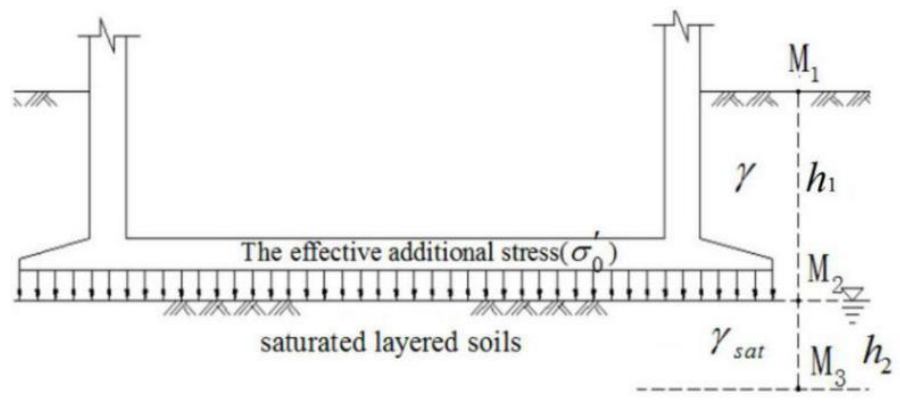

Fig. 2. Sketch map for saturation soils under the large scale foundation

In Fig. 2, the soil layer under the large scale foundation is assumed to be homogeneously saturated. It is worth noting that the down arrows shown in Fig. 2 only illustrate the direction of stress, the actually stresses (loading forces) at various locations of the foundation surfaces can be different for large foundations, i.e., the non-linear or irregular distributions of the effective additional stresses discussed in this work (ref: Fig 10c). $M_{1}, M_{2}$ and $M_{3}$ represent the soil elements at the natural ground level, the stable water level and the depth of $h_{2}$ below the stable water level respectively. The section of $M_{1} M_{2}$ is unsaturated soil, its natural unit weight is $\gamma$. The section of $M_{2} M_{3}$ is saturated soil, its unit weight is $\gamma_{\text {sat }}$. The volume-weight of water is $\gamma_{w}$. Therefore the effective stresses at the levels of $M_{1}, M_{2}$ and $M_{3}$ are $0, \gamma h_{1}$ and $\gamma h_{1}+\gamma_{s a t} h_{2}-\gamma_{w} h_{2}$ respectively. And due to the unit weight of soil and the degree of saturation are unchanged under homogeneous condition, the increment of the effective stress will be 0 . The effective additional stress $\left(\sigma_{0}^{\prime}\right)$ is the maximum effective additional stress increment. Therefore the effective additional stresses at $M_{1}, M_{2}$ and $M_{3}$ levels are $0, \Delta \sigma_{0 \max }^{M_{2}}$ and $\Delta \sigma_{0 \max }^{M_{3}}$, respectively. Where the $\Delta \sigma_{0 \max }^{M_{2}}$ and $\Delta \sigma_{0 \max }^{M_{3}}$ are the maximum additional stress increment at the point of $M_{2}$ and $M_{3}$.

Based on the stresses $\left(\sigma_{x}, \sigma_{y}, \sigma_{z}, \tau_{x y}, \tau_{y z}, \tau_{z x}\right)$ at any point $M(x, y, z)$ under a point loading force normal to the surface of an elastic half-space proposed by the French mathmetician Boussinesq.J (1878), the vertical stress of the foundation soil $\left(\sigma_{z}\right)$ can be expressed as:

$\sigma_{z}=\frac{3 P Z^{3}}{2 \pi R^{5}}$

Where $P$ is the point force, $Z$ is the depth under the bottom of foundation, and $R$ is the distance between the point force and any point $M$.

Under static loading condition, the effective additional stress is continuous and downward transmission down to the bottom of the foundation. On the bottom plane of foundation, it is assumed that the length of foundation is $L$, and the width is $B$. The foundation is divided into $m \times n$ sub-domains (shown in Fig. 3). The effective additional stress acting on each sub-domain is evenly distributed and can be regarded as an equivalent point load $P_{i j}(i=1,2, \ldots m$ and $j=1,2, \ldots n)$ at the center of each sub-domain. It is assumed that the center point $A_{i j}(i=1,2, \ldots m$ and $j=1,2, \ldots n)$ of the planar grid system coincides with the point load $\left(P_{i j}\right)$. $A_{i j}^{\prime}$ is the vertical corresponding point that under the point $A_{i j}$ at depth $z$ where the deformation will be calculated. Also, the point $\left(A_{i j}^{\prime}\right)$ coincides with corresponding point load $\left(P_{i j}^{\prime}\right)$. The sum of the all the point loads $\left(P_{i j}\right)$ is $m \times n$, and the corresponding point load $\left(P_{i j}^{\prime}\right)$ at the point $\left(A_{i j}^{\prime}\right)$ is a result that the accumulation of all the components of the equivalent point forces $\left(P_{i j}\right)$ loading at the planar grid separately. By repeating the above process, we can obtain the equivalent point forces of corresponding points on the new calculating surface at depth $z$. This process can be continued until the effective depth of the layered soils is all taken into account. This computational process can be termed as the method of subfield of planar mesh. The distribution of equivalent point forces $\left(P_{i j}\right)$ on the sub-domains are shown in 
Fig. 3.

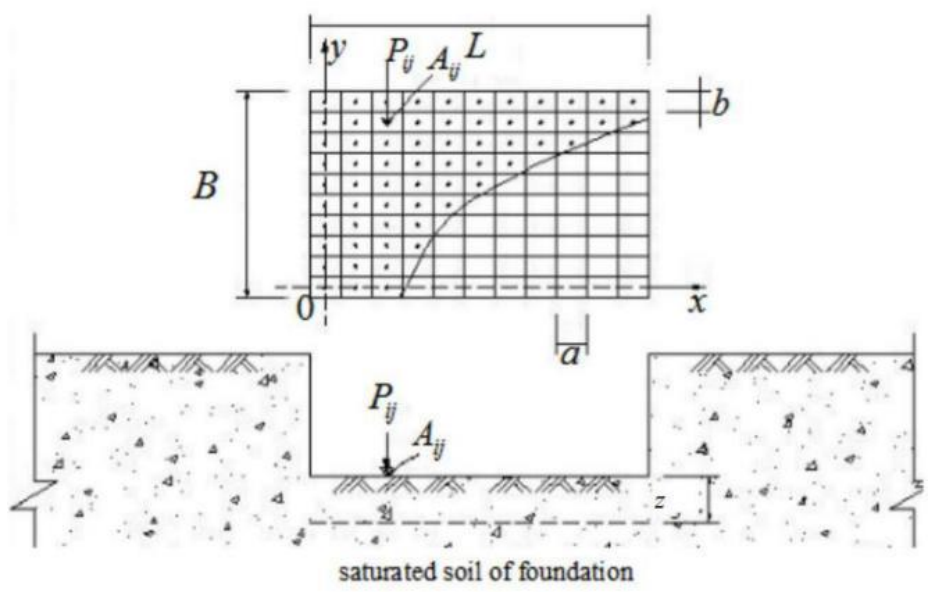

Fig. 3. Distribution of equivalent concentrated forces

The corresponding effective additional stress $\left(\sigma_{0 z}^{\prime}\right)$ below the depth of $z$ under any point $\left(A_{i j}\right)$ in Fig. 3 is the sum of all the additional stresses $\left(\sigma_{0 z}^{\prime}{ }^{i j}\right)$. It can be represented as:

$$
\sigma_{0 z}^{\prime}=\sum_{i=1}^{m} \sum_{j=1}^{n} \sigma_{0 z}^{\prime i j}=\sum_{i=1}^{m} \sum_{j=1}^{n} \frac{3 P_{i j} Z^{3}}{2 \pi R^{5}}
$$

If the depth of the effective compression is divided into $l$ layers, the final deformation $(S)$ of corresponding point $M_{i j k}\left(x_{i}, y_{j}, z_{k}\right)$ on the $k$-th $(k=1,2, \ldots l)$ layer can be expressed as:

$$
\begin{aligned}
& S=\sum S_{k}=\sum_{k=1}^{l} \frac{\bar{\sigma}_{0 k}^{\prime}}{E_{s k}} h_{k} \\
& \text { Where } \bar{\sigma}_{0 k}^{\prime}=\frac{\sigma_{0 k}^{\prime}+\sigma_{0(k-1)}^{\prime}}{2} \\
& \sigma_{0 k}^{\prime}=\sum_{i=1}^{m} \sum_{j=1}^{n} \frac{3 a b \cdot \sigma_{0}^{\prime i j} Z_{k}^{3}}{2 \pi R^{5}} \\
& \sigma_{0(k-1)}^{\prime}=\sum_{i=1}^{m} \sum_{j=1}^{n} \frac{3 a b \cdot \sigma_{0}^{i j} Z_{(k-1)}{ }^{3}}{2 \pi R^{5}} \\
& R^{2}=x_{i}{ }^{2}+y_{j}{ }^{2}+z_{k}{ }^{2}
\end{aligned}
$$

Where $a$ and $b$ are the dimension parameters for each sub-domain. The subscript $k$ and $k-1$ represent the location in depth where the specific layer of soil is located. Other symbols carry the same meaning as the previous descriptions.

Combining the simplified P-Z model discussed in section 2 (to calculate the compression modulus $E_{s}$ ) and the specific foundation deformation calculation methods developed in section 3, a complete foundation deformation calculation model for large building foundation was established. This newly proposed model (the full equation set from sections $2 \& 3$ ) was programmed and solved using MATLAB platform.

\section{The sensitivity analysis of model parameters}

When using the proposed mathematical model, a large number of model parameters need to be considered. In particular, when multilayered soils underneath foundations need to be treated separately, i.e. every layer of soil with different properties will have a set of model parameters. More model parameters used in the model are prone accumulated errors in the calculation of the final deformation. It is therefore necessary to 
conduct a sensitivity analysis to examine the roles of these parameters (associated with the elastic state, critical state and plastic modulus) in contributing the deformation of foundation.

A typical case example was used for the sensitivity analysis. The case was from the former technical Code for Design of Building Foundation (Li, 2009), as shown in Fig. 4. The rectangular raft type foundation size is $17.6 \times 110.2\left(\mathrm{~m}^{2}\right)$ and the total effective depth of the sandy soil is $4.6 \mathrm{~m}$ (the deformation sensitivity analysis is done at the depth of $0.5 \mathrm{~m}$ ). The deformation modulus $E_{0}$ is $28.8 \mathrm{Mpa}$. and the average additional stress is $P_{0}=189.4 \mathrm{kPa}$.

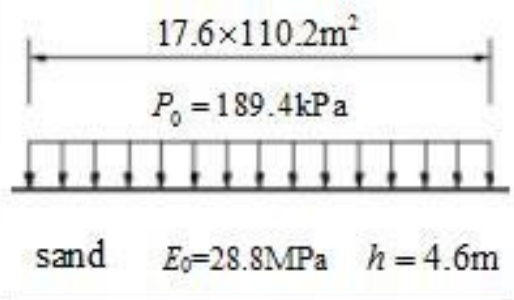

Fig. 4. The sketch of selected case example

When using the subfield of planar mesh method (discussed in section 3) to calculate the transfer of effective stress and deformation of subsoil, the reference values of model parameters of the above case example are needed. These reference values are shown in Table 1. These values were associated with the given case in the technical code to reflect the particular type of soil considered. The first eight key parameters are divided into three categories: elastic state, critical state and plastic modulus and their sensitivity to the calculation of foundation deformation will be discussed individually. The principles adopted during this calculation process include: varying one parameter at a time; the variation in value for any particular parameter will be up to $\pm 40 \%$ of the reference value in Table 1 (this $\pm 40 \%$ calculated range covers various types of soil condition in foundation practices); the deformation of soil layer at the depth of $0.5 \mathrm{~m}$ were calculated for the sensitivity analysis. In Table $1, \alpha$ is a material constant, a value of 0.45 was often used (Kumari Sunita and V.A. Sawant, 2013); $\Psi_{s}$ is a correction coefficient which can be found in the Code for Design of Building Foundation (GB 50007-2011).

Table 1 Reference values of parameters.

\begin{tabular}{|c|c|c|c|}
\hline Type & Parameter & Sign & Value \\
\hline \multirow{2}{*}{ Elastic state } & Deformation modulus/Mpa & $E_{0}$ & 28.8 \\
\hline & Poisson's ratio & $\mu$ & 0.3 \\
\hline \multirow{2}{*}{ Critical state } & Relative density/\% & $D_{\mathrm{r}}$ & 42.9 \\
\hline & Internal friction angle $/^{\circ}$ & $\varphi$ & 36.5 \\
\hline \multirow{5}{*}{ Plastic modulus } & Accumulated deviatoric strain & $\xi$ & 0.7 \\
\hline & \multirow{4}{*}{ Material parameters } & $\beta_{0}$ & 2 \\
\hline & & $\beta_{1}$ & 0.2 \\
\hline & & $H_{0}$ & 800 \\
\hline & & $\alpha$ & 0.45 \\
\hline Other & Correction coefficient & $\Psi_{s}$ & 0.21 \\
\hline
\end{tabular}

\subsection{The elastic state parameters}

The elastic modulus $\left(E_{0}\right)$ is an index that represents the material resistance for elastic deformation. Materials with larger value of elastic modulus $E_{0}$ have stronger ability to resist elastic deformation. Fig. 5( $\left.a\right)$ shows the corresponding vertical deformations when the elastic modulus $\left(E_{0}\right)$ is varied. It is obvious that 
with the increase of $E_{0}$, the vertical deformation is decreased. And larger vertical deformation is evident when the $E_{0}$ is decreased. Within the $\pm 40 \%$ variation range to its reference value $28.8 \mathrm{kPa}$, the absolute variation of vertical deformation $|\Delta \mathrm{S}|$ is $1.9514 \mathrm{~mm}$.
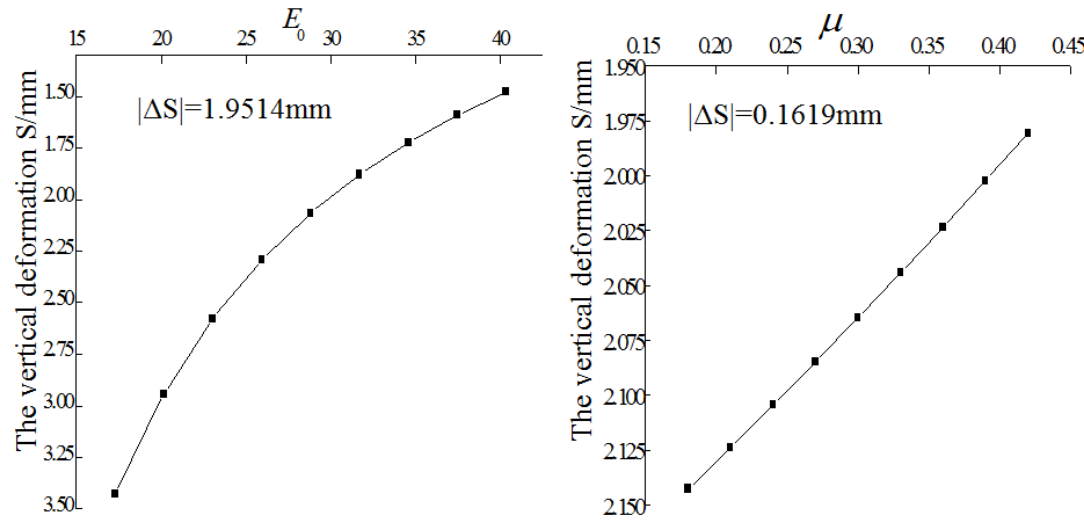

Fig. 5. The relationships between elastic parameters $\left(E_{0}\right.$ and $\left.\mu\right)$ and vertical deformation $S$.

Poisson's ratio $(\mu)$ is a parameter that reflects the ratio of lateral and vertical deformation. From Fig. 5(b), it can be seen that the vertical deformation of the soil is decreasing with the increase of $\mu$, and it is almost a linear relationship. Within the $\pm 40 \%$ variation range the absolute variation of vertical deformation $(|\Delta \mathrm{S}|)$ is $0.1619 \mathrm{~mm}$. Relatively the vertical deformation is less sensitive with the Poisson's ratio $(\mu)$ compared with the elastic modulus $\left(E_{0}\right)$. As shown in formulas (6 and 13 14), the above two elastic parameters are part of the elastic matrix $\left[D^{e}\right]$ which has direct influence on the elastic-plastic matrix $\left[D^{e p}\right]$, and the compressive modulus $\left(E_{s}\right)$ can then be calculated using the simplified $P-Z$ model.

\subsection{The critical state parameters}

The two parameters that define the critical state are the relative density $\left(D_{r}\right)$ and internal friction angle $(\varphi)$. For the original $P-Z$ sandy model, $M_{g}$ is a model parameter for the corresponding critical state. From formula (2), $M_{g}$ is a function of the internal friction angle $(\varphi)$ and Lode angle $(\theta)$, parameter $M_{f}$ can be estimated by the relative density $\left(D_{r}\right)$ and parameter $M_{g}$.

The relative density $\left(D_{r}\right)$ is an index that reflects the degree of looseness of soil, the smaller value with $D_{r}$, the looser of the soil. As shown in Fig. 6, both parameters (the $D_{r}$ and $\varphi$ ) show a near linear relationship with the vertical deformation. Within calculated variation of both parameters, the absolute change of vertical deformation $(|\Delta \mathrm{S}|)$ is $0.0921 \mathrm{~mm}$ for relative densigy $D_{r}$ and $0.3558 \mathrm{~mm}$ for $\varphi$ which indicates a relative stronger sensitivity for the internal friction angle.
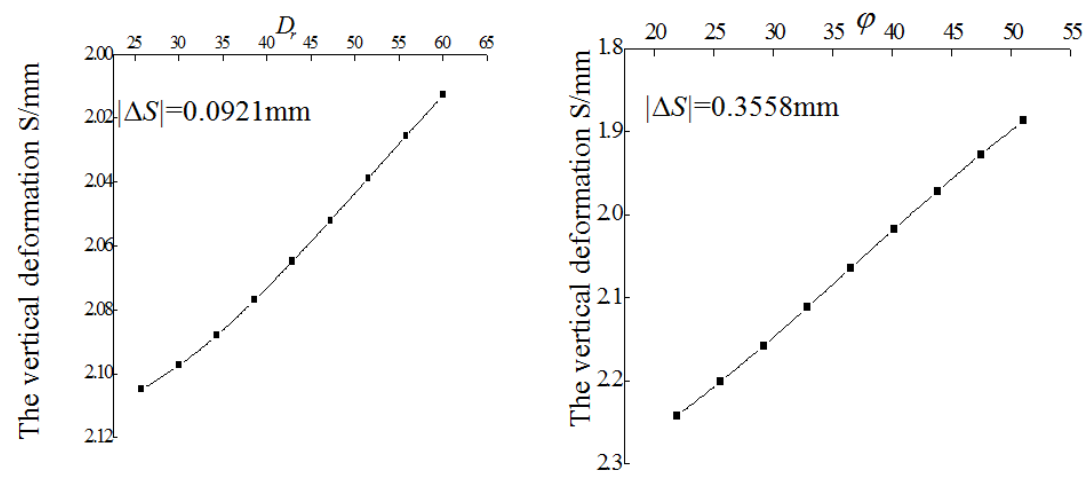

Fig. 6 Relationships between CSL parameters $\left(D_{r}\right.$ and $\left.\varphi\right)$ and deformation $S$

\subsection{The plastic modulus parameters}

The plastic modulus parameters include $\xi, H_{0}, \beta_{0}$ and $\beta_{1}$ (as in Table 1). They reflect the plastic modulus of soil under isotropic compression. Fig.7 shows the vertical deformations with the changes of the 4 plastic modulus parameters. Broadly speaking, with the $\pm 40 \%$ variation range of each parameter, the overall vertical deformations for all 4 parameters are small compared with the other model parameters from the categories discussed in sections $4.1, \& 4.2$ : the absolute deformations $|\Delta S|=0.0037 \mathrm{~mm}, 0.0093 \mathrm{~mm}$, 
$0.0008 \mathrm{~mm} \& 0.0027 \mathrm{~mm}$ for $\xi, H_{0}, \beta_{0}$ and $\beta_{1}$ respectively.
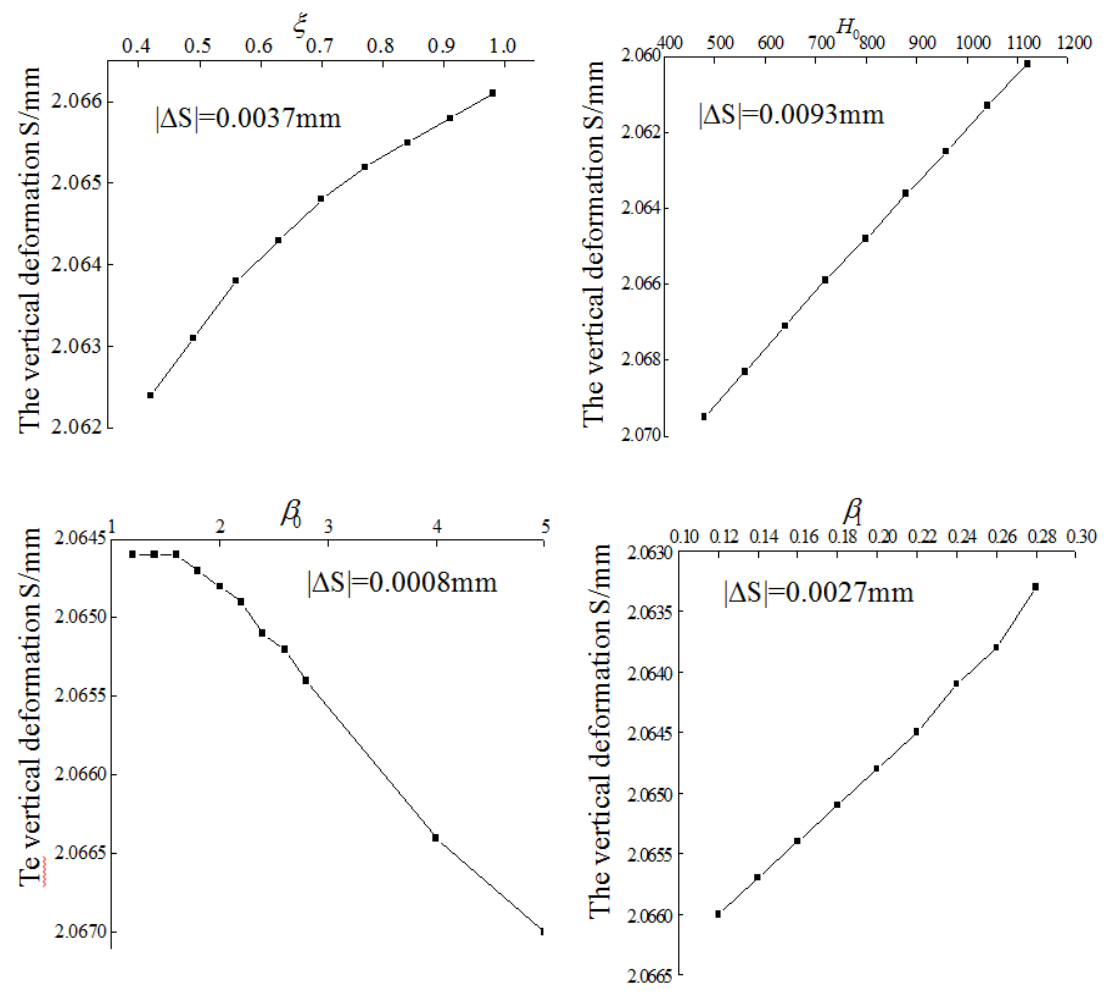

Fig. 7. Relationships between plastic modulus parameters $\left(\xi, H_{0}, \beta_{0}\right.$, and $\left.\beta_{1}\right)$ and deformation $S$

The overall trend of vertical deformation with $\xi, H_{0}$, and $\beta_{1}$ are similar - increasing these parameters will decrease $|\Delta \mathrm{S}|$. However, $\beta_{0}$ is on the contrary, the increase of $\beta_{0}$ will increase $|\Delta \mathrm{S}|$ when $1.5<\beta_{0} \leq 5.0$. And it is evident from Fig. 7 that the vertical deformation does not change when $\beta_{0} \leq 1.5$. This observation is consistent with Orang Farzaneh and Amin Iraji (2016). And this work also examined parameter $\beta_{1}$ but with a smaller range: $\beta_{1}$ is between 0.1 and 0.2 . The formulas (7), (8) \& (9) show the relationship between these 4 parameters $\xi, H_{0}, \beta_{0}$, and $\beta_{1}$. The results shown here indicates that the impact of the plastic modulus $\left(H_{\mathrm{L}}\right)$ on the elastic-plastic matrix $\left[D^{e p}\right]$ in formula (6) is insignificant.

\subsection{The relative sensitivity of all examined parameters}

Fig. 8 shows the relative variations of vertical deformation at depth of $0.5 \mathrm{~m}$ when the examined parameters were changed $\pm 40 \%$ against their reference values given in Table 1 . It is obvious the elastic modulus $E_{0}$ is the most influential parameter to cause vertical deformation. The relative changes of deformation are between $66.05 \%$ to $-28.46 \%$ when is varied from $-40 \%$ to $40 \%$ against its reference value $28.8 \mathrm{Mpa}$. The corresponding variations for the internal friction angle $(\varphi)$ is about $\pm 10 \%$ and for the Poisson's ratio $(\mu)$, the range is about $\pm 4 \%$. The relative vertical deformation variations are below $\pm 3 \%$ for the relative density $D_{r}$, and the 4 parameters from the plastic modulus category $\left(\xi, H_{0}, \beta_{0}\right.$, and $\left.\beta_{1}\right)$, the relative vertical deformation variations are less than $\pm 1 \%$ (Fig $8 \mathrm{~b}$ on the right and side shows the down scaled graph so the small variations can be examined). It is therefore reasonable to use one set of commonly recommended values under the plastic modulus category from the original P-Z model in order to simplify the subsequent numerical calculation and avoiding the potential accumulated errors from these parameters. In this work, when calculating the vertical deformation of foundation, the data recommended in Table 1 for the 4 plastic modulus parameters are used (As shown in Table 2). For parameters from the other two categories (elastic state and critical state), there chosen values were estimated based on the site conditions, i.e. the specific soil properties. 

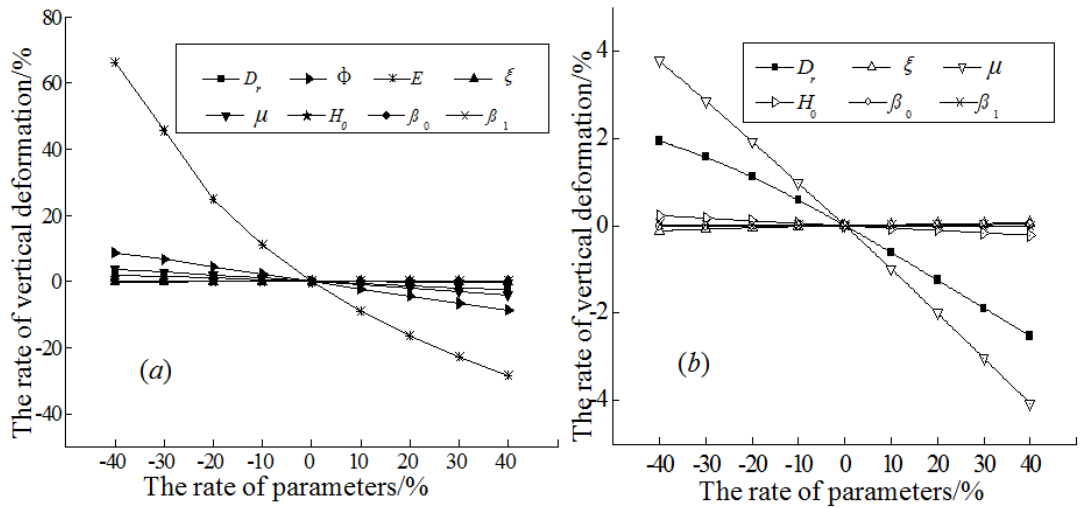

Fig. 8. The relative deformations $(\%)$ with the relative variations $( \pm 40 \%)$ of the examined 8 parameters.

\section{Model validation using an engineering example}

Liaoning North International Media Center is a large office building with 22 floors, reinforced-concrete frame-core wall structure, waffle-slab raft foundation. The depth of drilling includes four natural layers from top to bottom, which are round gravel, pebble, gravel sand and round gravel(2.) And the bearing layer of building is round gravel (refer Fig. 9). The depth of foundation is $-11.30 \mathrm{~m}$. The composition of foundation soil is also illustrated in the Fig. 9. During the construction process, the effective additional stress $\left(\sigma_{0}^{\prime}\right.$, equivalent with the maximum increment of additional stress $)$ at the foundation base and vertical deformation $S$ were monitored to ensure the safety of the structure. The key mechanical parameters of the foundation soil are given in Table 2. In this work, the recommended values in Table 1 for the plastic modulus parameters were used due to their relative small influences on the deformation of foundation (discussed in section 4), other parameters were estimated to reflect the specific foundation soils of this particular project.

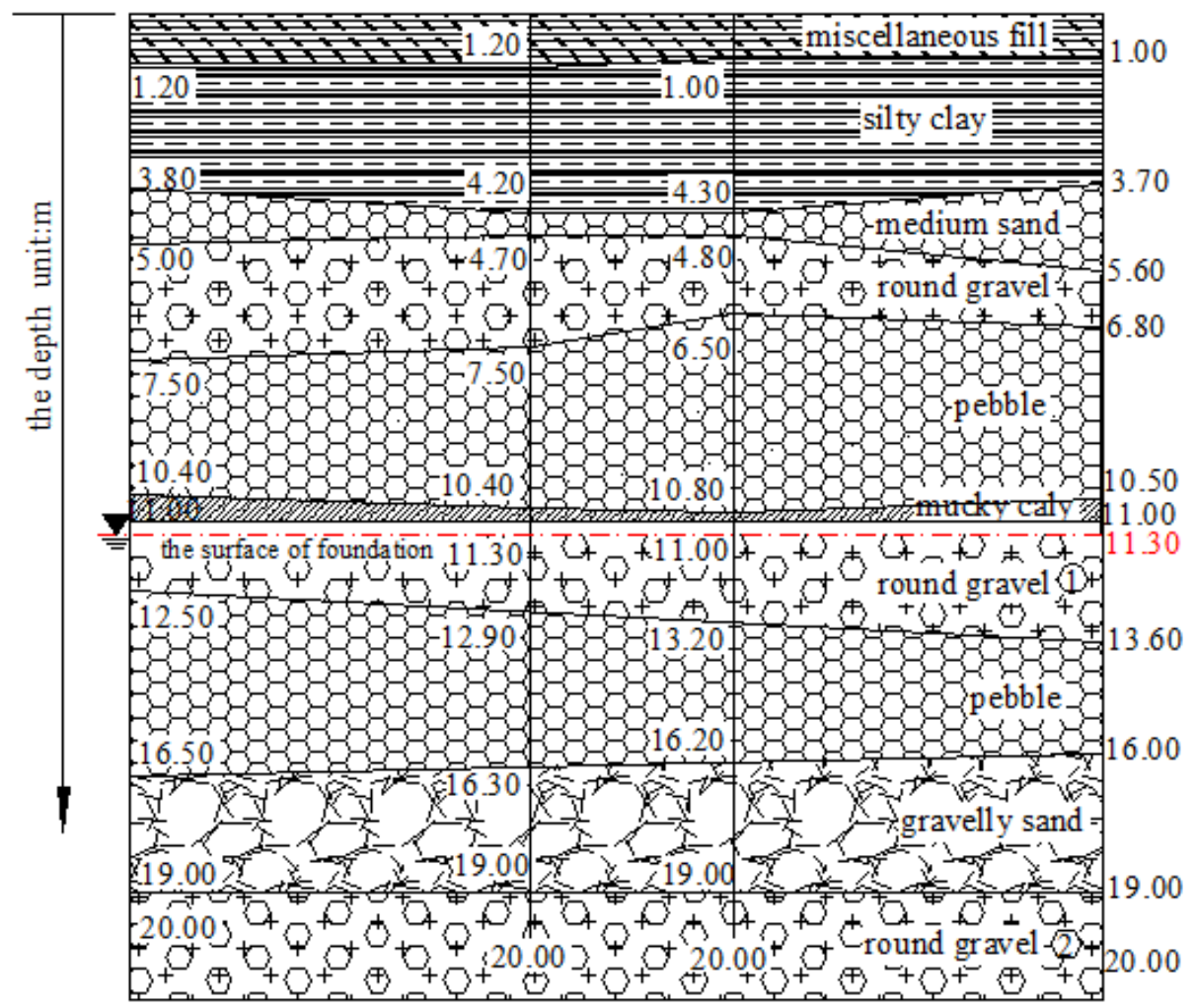

Fig. 9. The composition of foundation soil 
Table 2 The key mechanical parameters of foundation soil used for the simplified mathematical model

\begin{tabular}{ccccccccc}
\hline Soil layers & $E_{0} / \mathrm{Mpa}$ & $\mu$ & $D_{r} / \%$ & $\beta_{0}$ & $\beta_{1}$ & $H_{0}$ & $\xi$ & $\rho^{\circ}$ \\
& & & & & & & & \\
\hline Round gravel(1) & 36.9 & 0.2 & 42.9 & & & & & 39.0 \\
Pebble & 47.3 & 0.2 & 34.1 & & & & & 39.5 \\
Gravel sand & 36.7 & 0.3 & 63.7 & & & & & 38.0 \\
Round gravel(2) & 36.9 & 0.2 & 42.9 & & & & & 39.0 \\
\hline
\end{tabular}

Seven testing points were selected to monitor the effective additional stresses of foundation. The measurement equipment is the single film pressure cell that named GYH-2 (its size is $\phi 110 \times 25 \mathrm{~mm}$ ). The nominal rating of precision and relative error of this pressure cell are less than $0.2 \%$ and $1.0 \%$. The measurement range is $0 \sim 300 \mathrm{kPa}$. The distribution of the single film pressure cells and the cross-section of the foundation with sensor cells are shown in Fig. 10(a). The monitoring results are shown in Fig. 10(b). The measured data for the $7^{\#}$ pressure cell show irregular data which indicates an obvious failure of the pressure cell, therefore its corresponding measured data were ignored. Using the final measured values of the effective additional stresses (the end date) from the 6 pressure cells, the spatial distribution of the effective additional stresses were produced using the Lagrangian polynomial interpolation by subtracting the self-weight stress of the overlaying soil, as shown in Fig. 10(c).

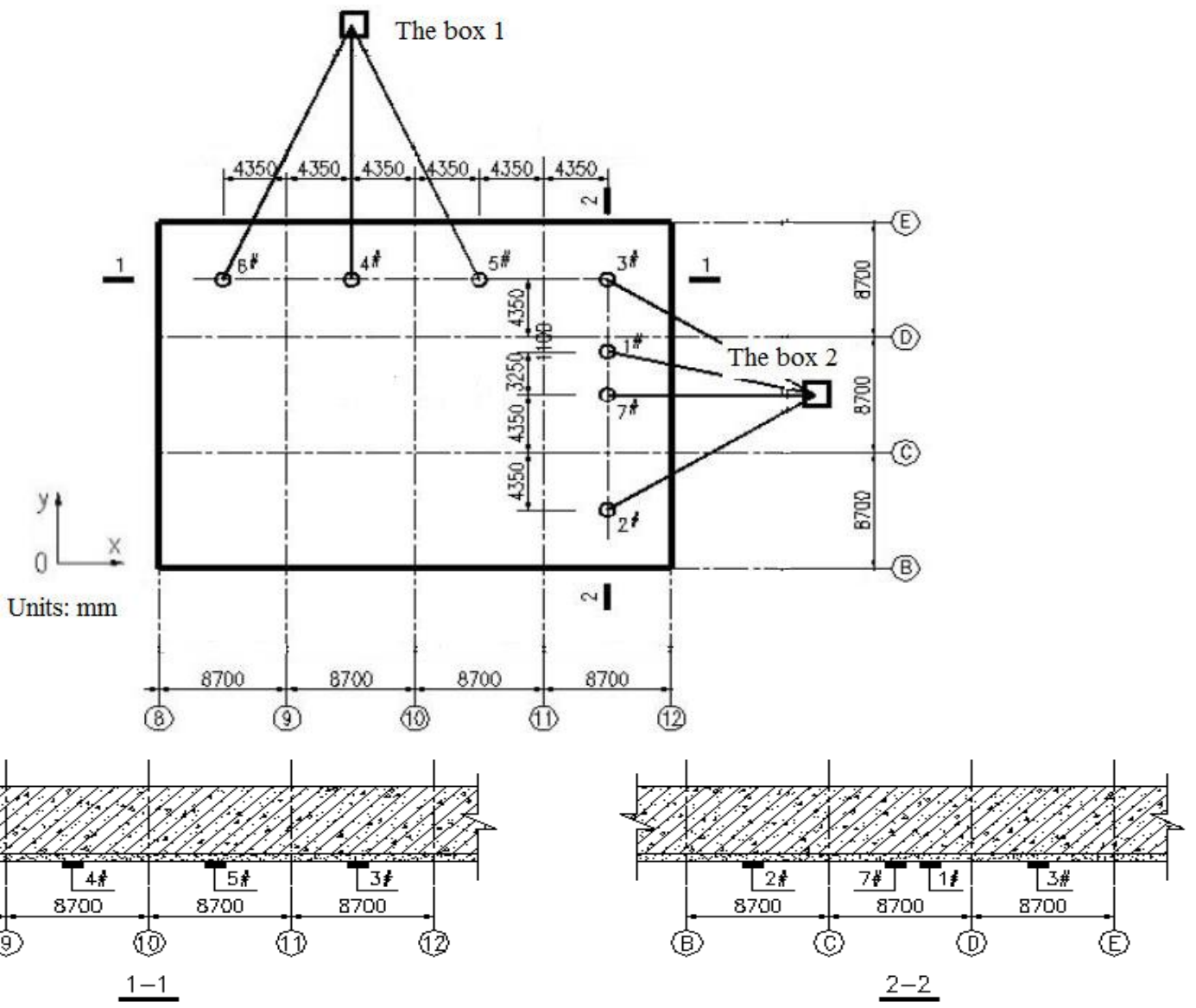

(a) The location map of stress sensor 


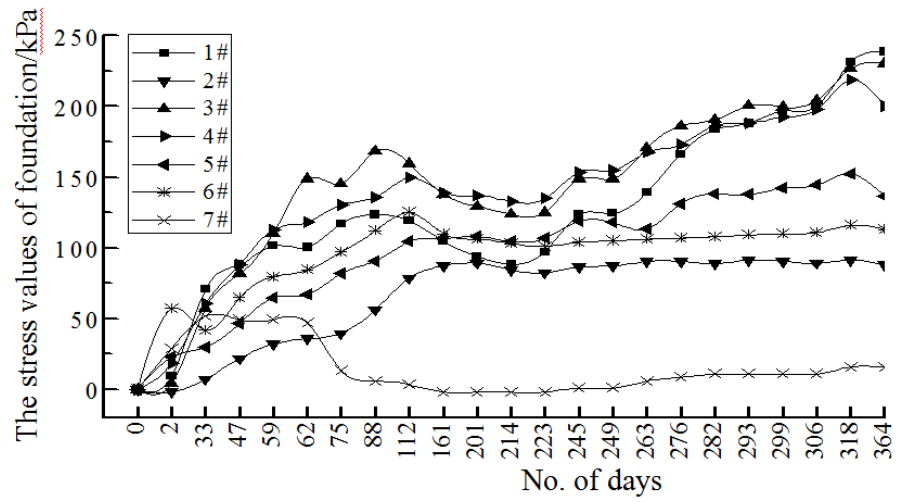

(b) The results of testing points

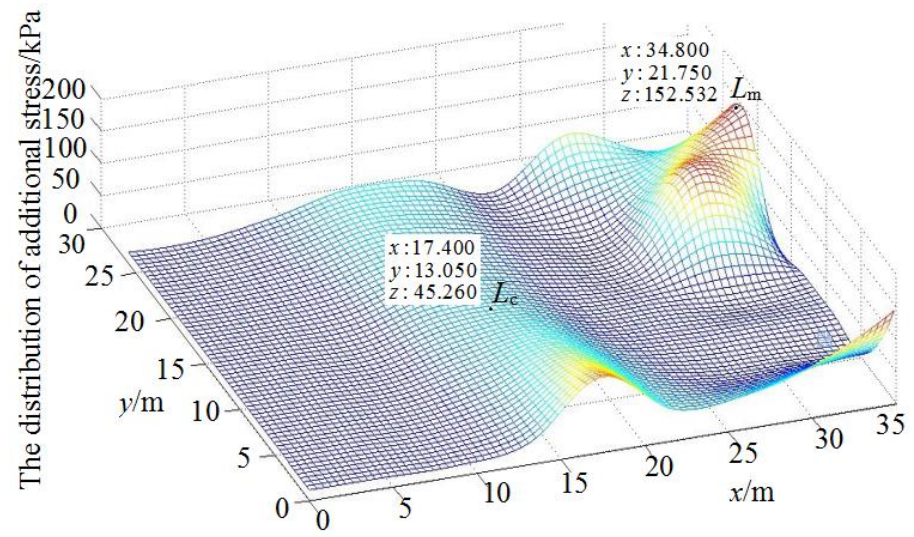

(c) Spatial surface of the additional stresses

Fig. 10. The testing values and distribution of effective additional stress under the large foundation

It is obvious from Fig. 10(c) that the loading distribution from these measured stresses is far from linear (for linear assumption, the loading distribution would be uniform). The maximum effective additional stress is $152.532 \mathrm{kPa}$ with the corresponding coordinates of $x=34.800 \mathrm{~m}, y=21.750 \mathrm{~m}$ (point $L_{\mathrm{m}}$ in the figure). And the effective additional stress at the center of foundation $(x=17.400 \mathrm{~m}, \mathrm{y}=13.050 \mathrm{~m}$ as the point $L_{\mathrm{c}}$ in Fig. 10(c)) is $45.260 \mathrm{kPa}$. The difference of the effective additional stresses between the two points is $107.272 \mathrm{kPa}$. This is obviously a significant difference in both relative and absolute terms which may result strong implications on the actual quantity of the maximum deformation and its location. For some simple and small foundation types when the requirements are less strict, the complicated non-linear loading (i.e. the types represented by fig. 10(c)) may be simplified as a flat plane with uniform stresses. However, for large foundations the locations of the maximum additional stress and the maximum deformation often do not coincide each other, this more complexed non-linear loading method should be used, which is the case for the engineering example discussed in this research.

When the proposed mathematical model was used to calculate the deformation of layered soils under a large building foundation, it is assumed that the layers underneath soils is the horizontal stratification of equal thickness along the depth direction (the profiles of underneath soils are varied in vertical direction). Fig. 11 and Table 3 show the vertical deformations calculated by the newly proposed mathematical model using the subfield of planar mesh method (refer Fig. 3). In Fig. 11(a); $(b) ;(c)$ and $(d)$, the distributions of the calculated additional stresses and vertical deformations at various depths are shown: the base of foundation, beneath the base of $2.3 \mathrm{~m}, 4.7 \mathrm{~m}$ and $7.7 \mathrm{~m}$, respectively (please note: the $h$ values shown in the Fig. 11 are the thickness of the concerned soil layer. For example, the vertical deformation at the base of foundation is calculated using the first layer of soil with $2.3 \mathrm{~m}$ in thickness; the deformation at the depth of $2.3 \mathrm{~m}$ beneath the foundation base is calculated using the second layer of soil with $2.4 \mathrm{~m}$ in thickness, and so on). Table 3 shows a summary of the maximum deformations and their locations, and the maximum loading (additional stress) locations for different layers of soil. It is clear from Table 3 that the maximum loading point can be different for different soil layers, and the maximum deformation point does not always 
coincide with the maximum loading point. For example, in the round gravel(2)(also shown in fig. 11(d)), the maximum loading point coordinate is $(x=30.88 \mathrm{~m}, y=20.01 \mathrm{~m})$, While the maximum deformation point is $(x=17.40 \mathrm{~m}, y=12.18 \mathrm{~m})$. There is a distance of $15.59 \mathrm{~m}$ between the two locations.

Table 3 The maximum deformation and corresponding coordinates in every natural layer

\begin{tabular}{ccccc}
\hline Natural layers & $\begin{array}{c}\text { Round gravel(1) } \\
h=2.30 \mathrm{~m}\end{array}$ & $\begin{array}{c}\text { Pebble } \\
h=2.40 \mathrm{~m}\end{array}$ & $\begin{array}{c}\text { Gravel sand } \\
h=3.00 \mathrm{~m}\end{array}$ & $\begin{array}{c}\text { Round gravel(2) } \\
h=12.10 \mathrm{~m}\end{array}$ \\
\hline $\begin{array}{c}\text { The maximum deformation } \\
(\mathrm{mm})\end{array}$ & 6.7028 & 3.8875 & 3.4219 & 11.4477 \\
$\begin{array}{c}\text { The point of maximum deformation } \\
(x, y)\end{array}$ & $(30.88,18.27)$ & $(31.32,19.14)$ & $(31.32,20.01)$ & $(17.40,12.18)$ \\
$\begin{array}{c}\text { The point of maximum loading } \\
(x, y)\end{array}$ & $(34.80,21.75)$ & $(31.32,19.14)$ & $(31.32,19.57)$ & $(30.88,20.01)$ \\
\hline
\end{tabular}

The shifting between the maximum deformation and the maximum loading points is primarily due to the highly non-linear effective additional stresses acting on the foundation bottom. This type of non-linear loading is continuously transmitted and superimposed in the depth direction during the calculation process, which causes the maximum loading and the maximum deformation points continuously moving. This is the reason why the numerical solutions of the deformation by using proposed model can have such significant variations as illustrated using the two dimensional x-y plane (Fig 11). As the depth increases, the maximum deformation and stress points of each sub-layer continuously move toward the center point of the foundation plane. Consequently, the largest deviations appeared to be between the maximum deformation point and the maximum loading point.

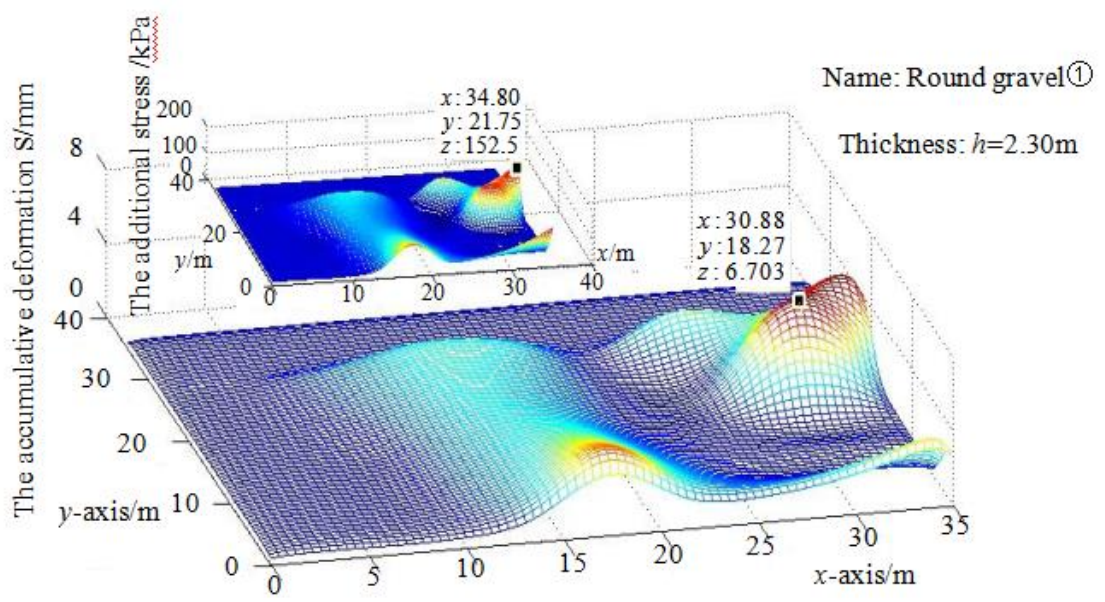

(a) The distribution of additional stress and accumulative deformation in round gravel(1) 


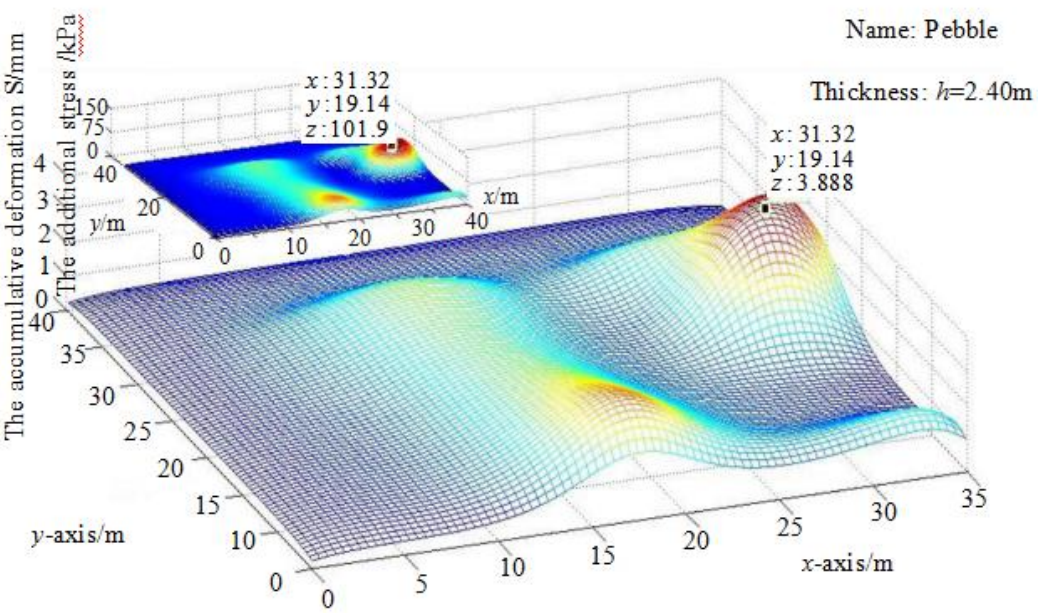

(b) The distribution of subsidiary stress and accumulative deformation in pebble

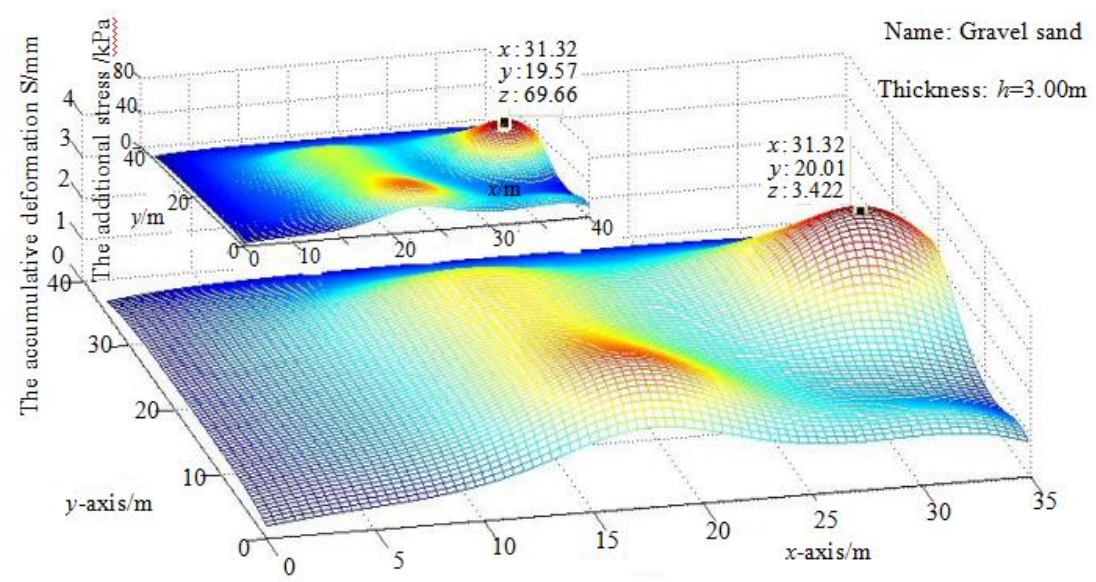

(c) The distribution of subsidiary stress and accumulative deformation in gravel sand

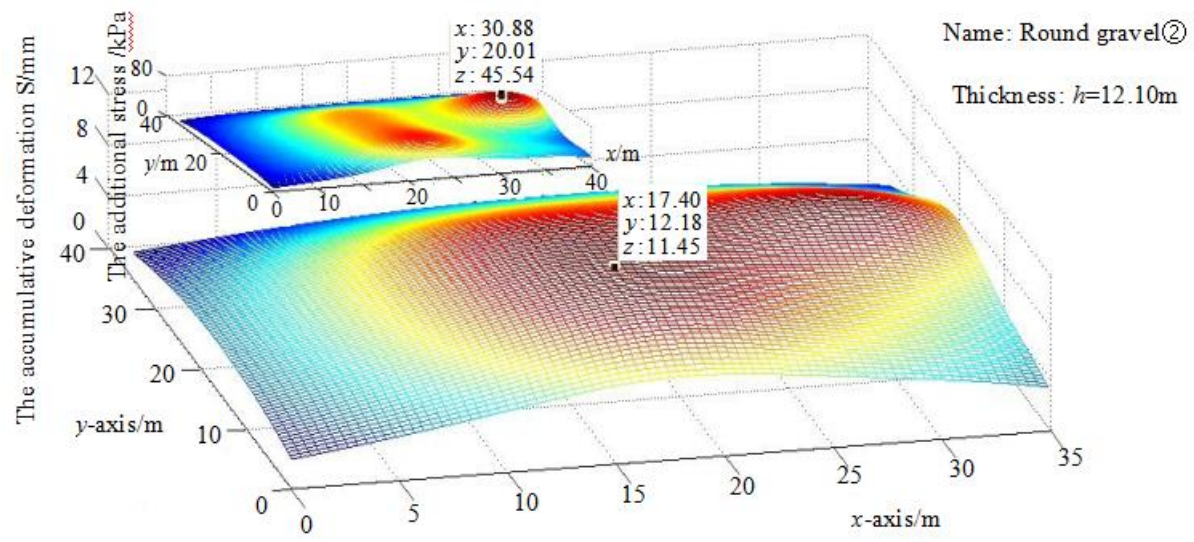

(d) The distribution of subsidiary stress and accumulative deformation in round gravel(2)

Fig. 11. The distribution of additional stresses and vertical accumulative deformations for different soil layers

There were six monitoring points ( $\mathrm{C} 1$ to $\mathrm{C} 6)$ selected to measure the vertical deformations of foundation for this engineering example (their coordinates were shown in Fig. 12(b)). The observing equipment is WILD N3 precise level (Swisstek Inc.). The key parameters of this equipment include: Average m.s.e. (standard deviation) is $\pm 0.2 \mathrm{~mm} / \mathrm{km}$; the telescope magnification is $46 \mathrm{x}$, the shortest focussing distance 
is $5 \mathrm{~m}$; sensitivity of level bubble per $2 \mathrm{~mm}$ is 10 ", the reading accuracy is $0.01 \mathrm{~mm}$. These measuring points were paired on the opposite walls with $x$ coordinates at $6.960 \mathrm{~m}, 17.400 \mathrm{~m} \& 29.145 \mathrm{~m}, y$ coordinates are at $0.0 \mathrm{~m}$ and $26.1 \mathrm{~m}$ respectively (Fig. 12(b)). The observation locations on the walls are $0.2 \mathrm{~m}$ above the ground. These locations were marked by steel bars buried into the wall structure with their tips visible on the wall. The observations network consists of the observation point ( $\mathrm{C} 1$ to $\mathrm{C} 6$, observed individually), the work point (where the equipment is located) and the stationary reference point (the reading will be read against).

Fig. 12(a) shows the measurements of accumulative deformations from the six monitoring locations during the construction phase. The end date (the $297^{\text {th }}$ day) here is the date of the construction completion, which is the same end date for the final additional stresses measurements - the $364^{\text {th }}$ day in Fig. 10(b). The difference in the number of days between the two measurements are due to the different starting time - the WILD N3 precise level equipments used to monitor the vertical deformation were installed 67 days after the stresses sensor installation (the single film pressure cells).

The final calculated vertical accumulative distribution of deformations for the whole depth $(22.8 \mathrm{~m}$ beneath foundation base) is shown in Fig. 12(b). The maximum vertical accumulative deformation is $24.750 \mathrm{~mm}$ with the corresponding coordinates of $x=30.88 \mathrm{~m}, y=18.70 \mathrm{~m}$ (point $S$ in the figure). The distance between point $S$ and the center point $14.62 \mathrm{~m}$. This is therefore evident that assuming the foundation central point is the maximum loading and deformation location is inappropriate for the large foundation case considered in this research. Fig. 12(b) also marked the calculated deformations at the same $x, y$ coordinates where the measurements were taken (points $\mathrm{C} 1$ to $\mathrm{C} 6$ on the figure). It is worth noting that the points $\mathrm{C} 1$ to $\mathrm{C} 3$ are on the perimeter of the construction (the edge of foundation in Fig. 10(a)), the extra 'data' plot on Fig. 12(b) when $y>26.100 \mathrm{~m}$, which are due to the nature of the square matrix used for the calculation, can be ignored.
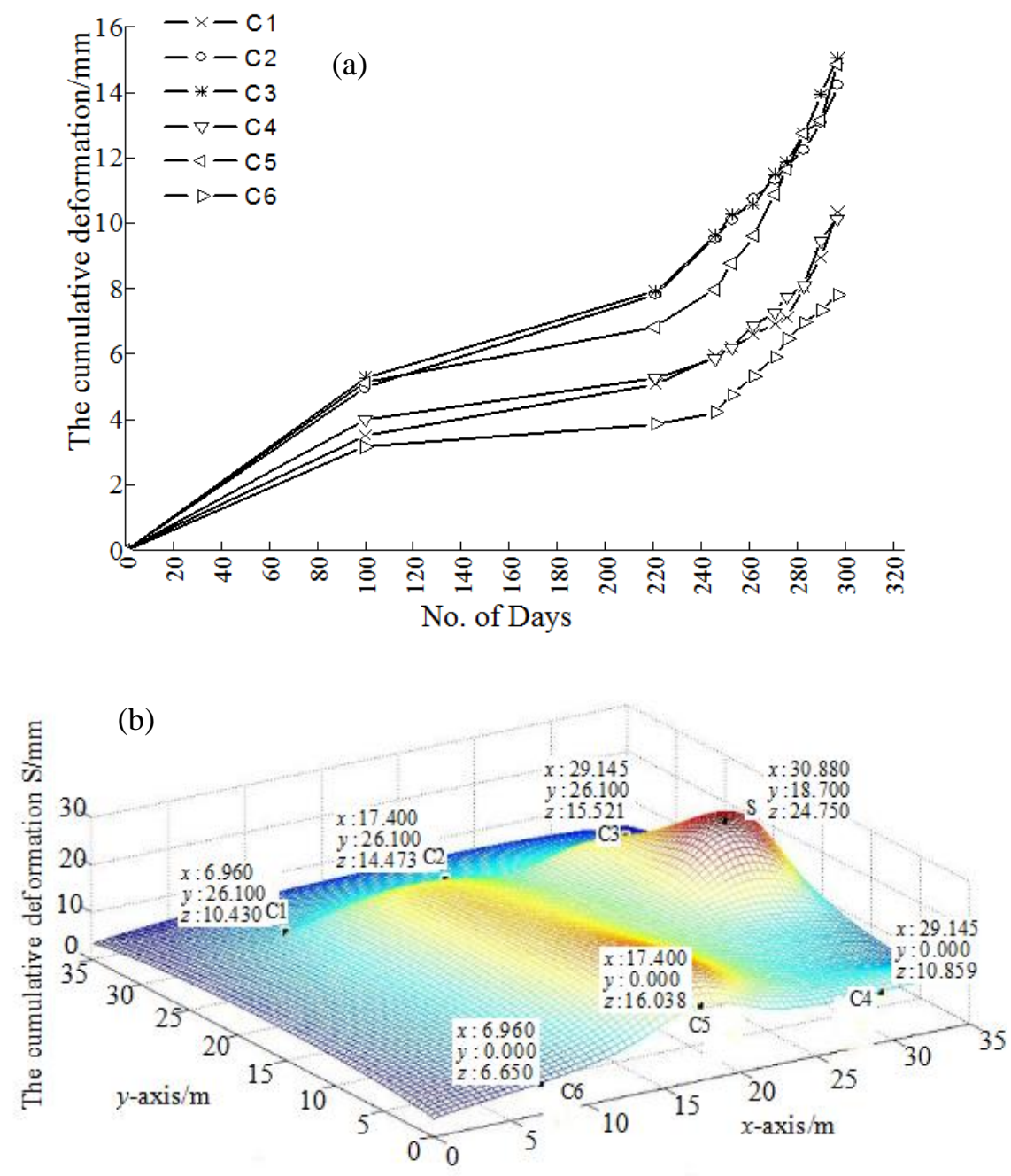
Fig. 12. The total deformation of foundation soils: (a) monitoring accumulative deformation over time and

The calculated vertical deformations on the projected lines of C1 to C3 and C4 to C6 were plotted in Fig. 13 against the measured deformations from the six observation points. Generally speaking, good agreement was achieved. The absolute and relative differences between measured and calculated vertical deformations are summarized Table 4. Larger discrepancies happen at point C5 \& C6 while the discrepancies for point $\mathrm{C} 1$ to $\mathrm{C} 4$ are relatively small. This is thought to be due to the Lagrangian polynomial interpolation for the spatial distribution of the effective additional stresses. There are only 6 measurements for the whole cross section of the foundation (Fig. 10(a)). There is a tendency that large errors may occur for the interpolated values further away from the measured value, for this particular case it is the left hand side bottom corner. The vertical deformation measurement locations of $\mathrm{C} 1$ to $\mathrm{C} 4$ are close to where the additional stresses sensors were located. This would mean the interpolated loadings (additional stresses) for these points were relatively accurate then the points C5 and C6 where there are no additional stresses sensors nearby. And there may be some other factors causing the discrepancies, such as: when the loading of the saturated sandy foundation is on, most of total vertical deformation would be realized instantaneously, but the time taken for completing the residual deformation can be quite long. The complex distribution of layered soil structure under the foundation is simplified, and the optimization of the calculation parameters also cause corresponding calculation errors.

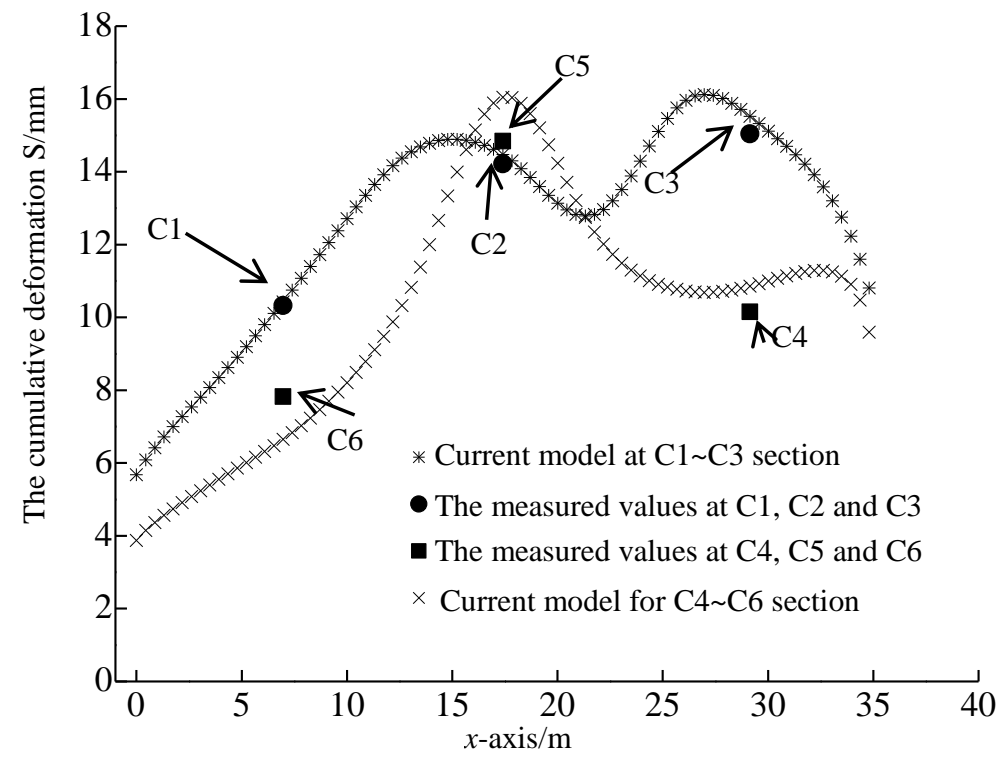

Fig. 13. The comparison of measured and calculated values

Table 4 The comparison of measured and calculated values

\begin{tabular}{ccccc}
\hline $\begin{array}{c}\text { Monitoring } \\
\text { points }\end{array}$ & $\begin{array}{c}\text { Measured } \\
\text { values } \\
\mathrm{mm}\end{array}$ & $\begin{array}{c}\text { Calculated } \\
\text { values } \\
\mathrm{mm}\end{array}$ & $\begin{array}{c}\text { Difference } \\
\mathrm{mm}\end{array}$ & $\begin{array}{c}\text { Relative } \\
\text { Error }\end{array}$ \\
\hline C1 & 10.33 & 10.4298 & 0.0998 & 0.97 \\
C2 & 14.22 & 14.4733 & 0.2533 & 1.78 \\
C3 & 15.04 & 15.5209 & 0.4809 & 3.20 \\
C4 & 10.15 & 10.8591 & 0.7091 & 6.99 \\
C5 & 14.84 & 16.0381 & 1.1981 & 8.07 \\
C6 & 7.82 & 6.6496 & -1.1704 & 14.97 \\
\hline
\end{tabular}


The interpolated additional stress at the center of foundation $(x=17.400 \mathrm{~m}, y=13.050 \mathrm{~m}$ as in Fig. $10(\mathrm{c})$ is $45.26 \mathrm{kPa}$. Using the newly development mathematical model the calculated corresponding vertical deformation is $S_{\text {center }}=17.19 \mathrm{~mm}$. A quick verification exercise was carried using the layered-wise summation method adopted by the Code for Design of Building Foundation (GB 50007-2011), the calculated vertical deformation at the center is $S_{\text {center }}^{\prime}=17.56 \mathrm{~mm}$. The results are quite similar for this specific case $(2.11 \%$ difference relatively), however, the calculation method in the code is similar with the existing models discussed in section 1 where linear loading condition is often assumed. It is clear from this the engineering example that the loading is non-linear and the existing models could not accurately predict the maximum deformation and its location under such loading conditions. The newly proposed mathematical model in this research has the advantages of calculating large and complex foundation deformations with non-linear loading.

\section{Conclusions}

This paper proposed a new mathematical model to calculate the deformation of large scale building foundations. The simplied P-Z model under static loading along with the newly developed foundation deformation calculations using the subfield of planar mesh method forms the proposed mathematical model. Using the proposed model, a sensitivity study was performed to identify the influences of various parameters on the deformation of foundations. Out of the 8 parameters examined, the elastic modulus $E_{0}$ shows the strongest influence followed by the internal friction angle $\varphi$ and the Poisson's ratio $\mu$. The 4 parameters from the plastic modulus category: $\xi, H_{0}, \beta_{0}$, and $\beta_{1}$ showed the least influences. This exercise provides the confidence of using some recommended values for these plastic modulus parameters rather than estimating them individually for different layer of soils.

An engineering case with large scale building foundation was used to validate the proposed model. In this real case scenario seven single film pressure cells were used to measure the additional stresses at the foundation base during the construction process. In the meanwhile WILD N3 precise levels were used to monitor the actual deformations of foundation at 6 perimeter locations. The measured maximum additional stresses at the construction completion date were used to generate the spatial non-linear loading using Lagrangian polynomial interpolation by subtracting the self-weight stress of the overlaying soil. Using this non-linear loading derived from measurements, the calculated foundation deformations using the proposed model agreed well with the monitored actual foundation deformations. Relatively larger discrepancies up to $14.97 \%$ do exist at the foundation deformation monitoring points where the additional stresses measurements were not close by. When the additional stresses measurements are nearby the foundation deformation monitoring points, very good agreement between calculated and monitored deformations was achieved. It is also clear from the calculation that the maximum deformation point does not always coincide with the maximum loading point - the largest distance of $15.59 \mathrm{~m}$ between the two points was recorded for the bottom layer of soil from the case study. The maximum deformation point is also nowhere near near the centre of the foundation either - a distance of $14.62 \mathrm{~m}$ is observed from this engineering case.

The proposed new model is able to consider the likely non-linear loading for large scale foundations which can be regarded as the key advantage of this model over other existing foundation deformation calculation models. It also has the advantages of calculating mutilayered soils with different properties at various depths using the subfield of planar mesh method. The proposed model is robust in nature and provides a valid method to inform large scale building foundation design through its deformation calculations.

\section{Acknowledgements}

The authors acknowledge the financial support provided by "The Key Program of the National Natural Science Foundation of China (No. 90915005)", "The natural science foundation planned program of Liaoning province (No. 2013010311)" .

\section{References}

Akhaveissy, A.H. (2011).“Analysis of tunnel and super structures for excavation.” Scientia Iranica, Vol. 18, No. 1, pp. 1-8, DOI: 10.1016/j.scient.2011.03.001.

Akhaveissy, A.H., Desai, C.S., Sadrnejad, S.A. and Shakib, H. (2009). "Implementation and comparison of a generalized plasticity and disturbed state concept for the load-deformation behavior of foundations." 
Scientia Iranica, Transaction A: Civil Engineering, Vol. 16, No. 3, pp. 189-198.

Amin Iraji, Orang Farzaneh, Ehsan Seyedi Hosseininia.(2014).“A modification to dense sand dynamic simulation capability of Pastor-Zienkiewicz-Chan model.” Acta Geotechnica, Vol. 9, pp. 343-353, DOI: 10.1007/s11440-013-0291-y.

Bezvolev S.G. (2002)."Method of accounting for the deformability of an inhomogeneous elastoplastic bed in analyzing foundation slabs." Soil Mechanics and Foundation Engineering, Vol. 39, pp. 162-170, DOI: 10.1023/A:1021665429148.

Boussinesq.J. (1878). "Équilibre d'élasticité d'un sol isotrope sans pesanteur, supportant différents poids". Comptes Rendus de l'Académie des Sciences, Paris, Vol. 86, pp. 1260-1263.

Denis, A., Elachachi, S. M., Niandou, H. (2011)."Effects of longitudinal variability of soil on a continuous spread footing.” Engineering Geology, Vol. 122, pp. 179-190, DOI: 10.1016/j.enggeo.2011.05.015.

Díaz E., Tomás R. (2016). "A simple method to predict elastic settlements in foundations resting on two soils of differing deformability." European Journal of Environmental and Civil Engineering, Vol. 20, No. 3, pp. 263-281, DOI: 10.1080/19648189.2015.1035806.

GB 50007-2011. "Code for Design of Building foundation." Beijing: Standards Press of China, Ministry of Construction, China, 2011.

Gazetas, G. (1980). "Static and dynamic displacements of foundations on heterogeneous multilayered soils." Géotechnique, Vol. 30, pp. 159-177, DOI: 10.1680/geot.1980.30.2.159.

Kumari Sunita, Sawant V.A. (2013). "Use of infinite elements in simulating liquefaction phenomenon using coupled approach." Coupled Systems Mechanics, Vol. 2, No. 4, pp. 375-387, DOI: $10.12989 / \mathrm{csm} .2013 .2 .4 .375$.

Li Chun. (2009). Research on Subsidence of Building Foundaton with Layered Sandy Subgrade, PhD thesis, Northeastern University, Shenyang, China.

Li Hong-en, He Yong-jun, Fan Guang-ya, Li Tong-chun and Manuel Pastor. (2011). "Recent developments of generalized plasticity model for saturated and unsaturated soils." Water Science and Engineering, Vol. 4, No. 3, pp. 329-344, DOI: 10.3882/j.issn.1674-2370.2011.03.009.

Li Hong-en, Li Zheng, Xu Hai-feng, Fan Guang-ya and He Yong-jun. (2016). "Pastor-Zienkiewicz based constitutive model and determination method of its state parameters." Rock and Soil Mechanics, Vol. 37, No. 6, pp. 1623-1632, DOI: 10.16285/j.rsm.2016.06.012.

Ling HI, Liu H. (2003). "Pressure-level dependency and densification behavior of sand through generalized plasticitymodel." Journal of Engineering Mechanics, Vol. 129, No. 8, pp. 851-860, DOI: 10.1061/ 0733-9399 (2003) 129:8(851).

Ling HI, Yang S. (2006). "Unified sand model based on the critical state and generalized plasticity." Journal of Engineering Mechanics, Vol.132, No. 12, PP. 1380-1391, DOI: 10.1061/0733-9399.

Liu, H. and Ling, H.I. (2002). "A sand model based on generalized plasticity." Proc. 15th Engineering Mechanics Conference, ASCE, Columbia University, New York, USA.

Liu, H. and Song, E. (2005). "Seismic response of large underground structures in liquefiable soils subjected to horizontal and vertical earthquake excitations." Computers and Geotechnics, Vol. 32, No. 4, pp. 223-244, DOI: 10.1016/j.compgeo.2005.02.002. 
Mroz Z, Zienkiewicz OC. (1984). "Uniform formulation of constitutive equations for clays and sand." Mechanics of engineering materials, Desai CS, Gallagher RH(eds), Chapter 22,Wiley, New York, pp. 415-459.

Onopa IA, Skopintseva EV, Dokhnyanskii MP. (1983). "Settlement of buildings on heterogeneous bases." Soil Mechanics and Foundation Engineering, Vol. 20, No. 6, pp. 227-230, DOI:10.1007/BF01716390.

Orang Farzaneh, Amin Iraji. (2016). "Two-Phase Model for nonlinear dynamic simulation of reinforced soil walls based on a modified Pastor-Zienkiewicz-Chan model for granular soil." Journal of Engineering Mechanics, Vol. 142, No. 6, pp. 1-17, DOI: 10.1061/(ASCE)EM.1943-7889.0000985.

Pastor M. (1986)."A generalized plasticity, hierarchical model for sand under monotonic and cyclic loading." Proc. 2nd Int. Symp. on Numerical Models in Geomechanics, Ghent, pp. 131-150.

Pastor M, Zienkiewicz OC, Chan AHC. (1990). "General plasticity and the modelling of soil behavior." International Journal for Numerical \& Analytical Methods in Geomechanics, Vol. 14, pp. 151-190, DOI: 10.1002/nag.1610140302.

Pastor M, Zienkiewicz OC, Leung KH. (1985). "Simple model for transient soil loading in earthquake analysis. II: Non-associative models for sands." International Journal for Numerical \& Analytical Methods in Geomechanics, Vol. 9, No. 5, pp. 477-498, DOI: 10.1002/nag.1610090506.

Pradhan T.B.S., Tatsuoka F, Sato Y. (1989). "Experimental stress-dilatancy relations of sand subjected to cyclic loading." Soils and Foundations, Vol. 29, No. 1, pp. 45-64, DOI: 10.3208/sandf1972.29.45.

Tonni L, Cola S, and Pastor M. (2006) "A generalized plasticity approach for describing the behavior of silty soils forming the Venetian lagoon basin." Proc. 6th European Conference on Numer Meth in Geotech Eng., London, pp. 93-99, DOI: 10.1201/9781439833766.ch13.

Zienkiewicz OC, Leung KH, Pastor M. (1985). "Simple model for transient soil loading in earthquake analysis. I: Basic model and its application." International Journal for Numerical \& Analytical Methods in Geomechanics, Vol. 9, No. 5, pp. 453-476, DOI: 10.1002/nag.1610090505.

Zienkiewicz OC, Mroz Z. (1984). "Generalized plasticity formulation and applications to geomechanics." Mechanics of Engineering Materials, Vol. 44, No. 3, pp. 655-680. 